\title{
Detecting and Date-Stamping Rational Bubbles in Asset Price: An Empirical Investigation in the Tunisian Stock Market
}

\author{
Siwar Mehri Helali ${ }^{1}$ \\ ${ }^{1}$ Ecole Supérieure des Sciences Economiques et Commerciale de Tunis, Tunisie \\ Correspondence: Siwar Mehri Helali, Ecole Supérieure des Sciences Economiques et Commerciale de Tunis, \\ ESSEC Tunis, 4 Rue Abou Zakaria El Hafsi, Montfleury 1089, Tunis, Tunisie. Tel: 216-23-432-434. E-mail: \\ siwar.mehri@yahoo.fr
}

Received: June 15, 2019

Accepted: July 12, 2019

Online Published: July 18, 2019

doi:10.5539/ijef.v11n8p91

URL: https://doi.org/10.5539/ijef.v11n8p91

\begin{abstract}
This study tests the existence of periodically collapsing speculative bubbles in the Tunisian stock market. We use the Phillips, Wu, and Yu (2011) and Phillips, Shi, and Yu (2015) approaches, based on right-tailed unit root tests, in order to explore the existence and to date-stamp the origination and termination of bubbles. An empirical application was conducted in the Tunisian stock market, using monthly data on stock price-dividend ratio, for the period running from January 2004 to December 2014. The empirical findings provide evidence for the existence of exuberance in the Tunisian stock market over the period and date-stamp its origination and collapse.
\end{abstract}

Keywords: rational bubbles, Tunisian stock exchange market, date-stamping bubbles, SADF, GSADF

\section{Introduction}

The latest decades have seen a dramatic sequence of stocks market crises. This succession of stock market crises intrigues more and more specialists, theoreticians and practitioners. These latter are still trying to identify the causes of these crises and to analyze these complex phenomena in order to mitigate their harmful consequences on the economy, either by avoiding them or by reducing their scale. One of the interpretations to which researchers focuse to explain the occurrence of stock market crises, the most advanced but also the most controversial is the bursting of speculative bubble.

According to Kindleberger (1991), bubble is "a sharp rise in price of an asset or a range of assets in a continuous process, with the initial rise generating expectations of further rises and attracting new buyers - generally speculators, interested in profits from trading in the asset rather than its use or earning capacity. The rise is usually followed by a reversal of expectations and a sharp decline in price often resulting in financial crisis". The academic literature, has not found consensus about the explanation of bubble phenomena. Some researchers, such as Fama (2010) (Note 1), have even questioned the existence of speculative bubbles. Others agree that any significant deviation of price of an asset from its fundamental value reflects the presence of a bubble. (Blanchard, 1979; Blanchard \& Watson, 1982; Shiller, 1984; Summers, 1986; Camerer, 1989; Cutler et al., 1991).

Since the early 1980s, several theories have been developed to understand the bubble phenomena. The first bubble models emerged in the literature were proposed by Blanchard (1979) and Blanchard and Watson (1982). Blanchard (1979) proposed a deterministic bubble model that displays an explosive behavior. Blanchard and Watson (1982) generalize that model and suggest a rational stochastic model which allows bubble to burst and restart repeatedly. These models consider that the rationality of both behaviour and of expectation can explain the deviations of the price from the fundamental value. Some authors such as Shiller (1984), Summers (1986) and Camerer (1989) attribute the bubbles to the irrationality of investors. In these models, some social psychological phenomena are introduced as irrational factors to explain price bubble.

Since the contribution of Blanchard (1979) and Blanchard and Watson (1982), the academic literature that focuses on rational bubbles has been enriched by the contribution of many authors. Evans (1991) developed a theoretical formulation of bubbles that collapse periodically. Froot and Obstfeld (1991) suggest a specific type of rational bubbles, called "intrinsic bubbles", that depends exclusively on fundamental determinants (i.e. the level of dividend).

The development of theoretical framework has favored the emergence of extensive empirical literature trying to 
detect the existence of rational speculative bubbles. The literature review revealed several econometric methods that can be used in order to investigate the existence of rational bubbles. Among these techniques, we can mention variance bound tests proposed by Shiller (1981), specification tests developed by West (1987), duration dependence method proposed by McQueen and Thorley (1994) and unit root and cointegration tests popularised by Diba and Grossman (1988). Although most studies on detection of rational speculative bubbes were conducted using the cointegration tests, there is a serious limitation to these methods. Evans (1991) showed that unit root and cointegration tests are unable to detect bubbles that collapse periodically. To overcome the weaknesses associated with cointegration tests, a large number of scholars propose new methods that have some power in detecting periodically collapsing bubbles (Taylor \& Peel, 1998; Van Norden, 1996; Van Norden \& Vigfusson, 1998; Driffil \& Sola, 1998; and Hall et al., 1999).

In recent work, Phillips, Wu, and Yu (2011) (PWY (2011) hereafter) provided a new framework, named Supremum Augmented Dickey-Fuller Test (SADF), for detecting and dating rational bubbles. PWY (2011) used a forward recursive right-tailed unit root tests in order to identify explosive phase in the behavior of stock prices. The major advantage of this strategy is that it allows estimation of the origination date and the termination date of a bubble. Phillips, Shi, and Yu (2015) (PSY (2015) hereafter) extended the SADF strategy and developed the Generalized Supremum Augmented Dickey-Fuller Test (GSADF), in order to detect explosive behavior when multiples bubbles occur in the data.

The aim of this paper is to use the approaches developed by PWY(2011) and PSY(2015) in order to detect periodically collapsing bubbles, and to date-stamp the beginning and the end of bubbles in the Tunisian stock market during the period extending from January 2004 to December 2014. To the best of our knowledge, this is the first research that implements the date-stamping strategy developed by PWY(2011) and generalized by PSY(2015) in the Tunisian stock market.

The remainder of the paper is structured as follows. In section 2, we provide a review of the literature on econometric detection of rational bubbles. Section 3 presents the data used in this study and outlines the date-stamping strategies proposed by PWY (2011) and PSY (2015). In section 4, we present the empirical finding for the date-stamping strategies. Finally, concluding remarks are provided in section 5 .

\section{The Literature Review}

An extensive empirical literature (Note 2) has emerged in order to identify the occurrence of rational speculative bubbles. A first approach to detect deviations from fundamental value, is to use the concept of volatility and to apply excess volatility tests. This approach, named variance bounds tests, was initially suggested by Shiller (1981) and Leroy and Porter (1981) to validate the Efficient Market Hypothesis. It can also be used to detect the presence of rational speculative bubbles. The basic idea of this approach is that, in the presence of rational bubbles, the variance of the observed price will be higher than the variance of the fundamental value. West (1987) proposes an other method, the two-step test, for the detection of rational bubbles. This method compares two alternative estimators of the underlying asset pricing model. The first set of estimates contains a bubble factor, whereas the second set contains no bubble factor. A Hausman (1978) type specification test is then used for testing equality of the two sets of estimates. Under the null hypothesis of no bubbles, the two estimates obtained should be equal, while the null hypothesis of no bubbles is rejected when there is no discrepancy between the two estimates.

Another popular method used for detection of asset price bubbles, was proposed by Diba and Grossman (1988). These authors applied the concept of cointegration, introduced initially by Granger (1986) and Engle and Granger (1987), to identify the existence of a long-run equilibrium relationship between stock market prices and the fundamental value. If two series are cointegrated, then they cannot drift apart indefinitely and they must satisfy long-run equilibrium relationship. The presence of a long-run relationship between prices and dividends implies that the stock prices and the fundamental value are cointegrated which indicates that there are no bubbles. In contrast, a non stationary deviation between theses series is considered as the evidence for no cointegration of stocks prices and dividends. The null hypothesis of no rational bubbles in assets prices is then rejected. Diba and Grossman (1988) implement test for cointegration in stock prices and dividends using annual data for Standard and Poor's 500 index. They find strong evidence in favour of the cointegration of stock prices and dividends inconsistent with rational bubbles.

Many scholars have applied unit root and cointegration in different stock markets to investigate the existence of rational bubbles. For example, Froot and Obstfeld (1991) applied a unit root test in price-dividend ratio using Standard and Poor's 500 index data from 1900 to 1988. By adopting the methodology of Phillips and Perron (1988), these authors' reports evidence in favour of rational bubbles. Brooks and Katsaris (2003) detected a 
divergence between stock prices and their fundamental values on the London Stock Exchange over the period 1965-1999. They explain this divergence by the presence of speculative bubbles. The study of Boubaker et al. (2007) investigate the bubble phenomena using data for ten companies listed on the Tunisian stock market over the period 1971-2005 using the unit root and cointegration tests. The Augmented Dickey-Fuller (Dickey and Fuller, 1981) and Philips-Perron (Philips \& Perron, 1988) stationarity tests reject the bubble hypothesis, while the cointegration test of Engle and Granger (1987) provides evidence in favour of rational bubbles.

Although cointegration tests have been widely used by many of authors, Evans (1991) pointed that these tests fail to detect explosive bubbles when the sample includes periodically collapsing bubbles. Using simulated data, he showed that the unit root and cointegration tests have low power in detecting periodically collapsing bubbles. Since the publication of Evans' paper (1991), the empirical literature has been constantly enriched by new tests for the detection of rational speculative bubbles in order to overcome shortcomings of cointegration tests to detect periodically collapsing bubbles. For example, Taylor and Peel (1998) suggest a robust test for non-cointegration which may be more appropriate for bubbles that collapse periodically. Van Norden (1996) and Van Norden and Shaller (1999) suggest using a regime switching model. Hall et al. (1999) propose an approach based on a generalization of Dickey-Fuller test which makes use of a class of Markov regime-switching models. Bohl (2003) implements the momentum threshold autoregressive (MTAR) model developed by Enders and Granger (1998), and Enders and Siklos (2001) to detect empirically the existence of periodically collapsing bubbles.

Recently, PWY (2011) have proposed a novel approach, named "Supremum Augmented Dickey-Fuller Test" (SADF), to deal with the deficiencies of cointegration tests in order to testing bubble phenomena. The originality of the approach lies in the fact that it allows not only to detect the presence of exuberance in the data but also to date-stamp the origination and termination of exuberance periods. PWY(2011) implements the right-tailed unit root tests repeatedly on a forward expanding sequence to identify explosive behavior in stock prices. The empirical study conducted by PWY (2011) to the Nasdaq index in the 1990s, corroborates the existence of exuberance and date-stamps its origination and termination. Homm and Breitung (2012) compare several strategies for the detection of speculative bubbles. They show that the strategy proposed by PWY(2011) is the most reliable in detecting periodically collapsing bubbles.

A drawback of the PWY (2011) strategy is that it is effective only when the sample data period includes a single bubble episode. To overcome this weakness, PSY (2015) generalise the SADF approach and propose the "Generalized Supremum Augmented Dickey-Fuller" test (GSADF) to account for the presence of multiple bubbles in the sample. The GSADF approach is also based on recursive unit root tests to detect periodically collapsing bubbles. PSY (2015) conducted an empirical application on the Standard and Poor's 500 price-dividend ratio for the period between January 1871 and December 2010 to detect and to identify points of origination and collapse of bubbles. This dating strategy has identified well-known historical episodes of bubbles. The episodes of exuberance identified include the banking panic of 1907, the 1987 stock market crash, the great crash of 1929, the postwar boom in 1954, the Black Monday in October 1987, the so-called dot-com bubble (1995-2001) and the mortgage crisis known as the subprime crisis (2008-2009). In contrast, the SADF approach identifies only two episodes of bubbles over the same period: the financial panic of 1873 and the dot-com bubble.

Different research studies were conducted using the SADF and the GSADF strategies to identify episodes of exuberance in the stock markets. Chang et al. (2014) apply the GSADF strategy to test if there are multiple bubbles in the BRICS (Brazil, Russia, India, China and South Africa) stock markets. The results indicate that there are several bubbles on the BRICS stock markets and the dates of bubble correspond to particular events in the stock markets of these countries. Wang (2014) also adopt the methodology of PSY (2015) to detect the explosive periods in the price and dividend indexes. The sample includes 20 emerging countries for the period running from 1995 to 2014. Looking first at the MSCI (Morgan Stanley Capital International) emerging markets overall index, the authors identified two episodes of explosiveness in the middle 2000s. The results of tests conducted on the individual markets, show a strong evidence for exuberance periods among the majority of stock markets. Liu et al (2016) also used the SADF and GSADF tests to detect the presence of speculative bubbles on the Shanghai Stock Exchange. The GSADF test results confirm the two major episodes of exuberance and collapse in the Shanghai Stock Exchange, while the SADF test identifies a single bubble. The results suggest that the GSADF test is more powerful for the detection of multiple bubbles. 


\section{Data and Methodology}

\subsection{Data}

The empirical study conducted focuses on the Tunisian stock market. The data comprise the Tunisian stock index, Tunindex $\left(P_{t}\right)$, and the corresponding dividend index $\left(D_{t}\right)$. The data are sampled monthly over the period from January 2004 to December 2014. The monthly data for the Tunindex indice were collected from the Financial Statistics of the Central Bank of Tunisia. We have determined the dividend index $\left(D_{t}\right)$ from the dividend yield $\left(D Y_{t}\right)$, as follows:

$$
D_{t}=D Y_{t} * P_{t}
$$

To calculate the dividend yield, we followed the procedure adopted by Datastream. The dividend yield is, then, obtained by the ratio between the total amount of dividends paid by companies and the total market capitalizations of companies included in the Tunindex. Thus, the dividend yield was calculated using the following expression:

$$
D Y_{t}=\frac{\sum_{t=1}^{n} d_{t} * n_{t}}{\sum_{t=1}^{n} p_{t} * n_{t}}
$$

where: $D Y_{t}$ : dividend yield at period $\mathrm{t} ; d_{t}$ : dividend per share at period $\mathrm{t} ; n_{t}:$ number of shares in issue at period $\mathrm{t} ; p_{t}$ : price at period $\mathrm{t} ; n$ : number of constituents in index.

All of the data used to calculate the dividend index were collected from the annual reports of the Tunisia Stock Exchange. The series of the stock market index and dividend index are deflated using the consumer price index, which is obtained, from the Financial Statistics of the Central Bank of Tunisia. For the empirical investigation, we use price-dividend ratio as PSY(2015).

\subsection{Methodolgy}

In this study we apply a recursive test procedure suggested by PWY(2011) and generalized by PSY (2015). These methods are based on recursive unit root tests and can detect the date of occurrence of speculative bubbles and the date of their bursting.

\subsubsection{The PWY Test (2011): The Supremum Augmented Dickey-Fuller Test (SADF)}

The procedure suggested by PWY (2011) is based on recursive estimates of the Dickey and Fuller tests. The empirical specification used is the following Augmented Dickey-Fuller (ADF) regression:

$$
\Delta y_{t}=\mu+\varphi y_{t-1}+\sum_{i=1}^{p} \psi_{i} \Delta y_{t-i}+\varepsilon_{t}
$$

where $y_{t}$ denotes the time series, $\mu$ is the intercept, $\varphi$ is the autogressive coefficient, $p$ is the maximum number of lags, $\Delta$ is the difference operator, $\psi_{i}$ for $i=1, \ldots, p$ are the differenced lags coefficients and $\varepsilon_{t}$ is the error term.

Unit root tests are commonly used to determine whether a time series is stationary using an autoregressive model as given by the expression (3). This equation is used to test the null hypothesis of a unit root against the alternative hypothesis of stationarity. In contrast the Augmented Supremum Dickey-Fuller (SADF) test, proposed by PWY (2011), is a right-tailed unit root where the null hypothesis is the existence of a unit root against the alternative hypothesis of mildly explosive behavior in $y_{t}$. Formelly in the test, the null hypothesis of unit root test is $H_{0}: \varphi=1$ (absence of bubbles), while the alternative hypothesis is $H_{0}: \varphi>1$ (presence of bubbles).

In the approach proposed by PWY(2011), the right-tailed ADF statistics are calculated in multiple recursive regressions on different subsamples. Each subsample starts with initital observation, while the last observation varies. Formelly, let $r_{1}$ and $r_{2}$ represent respectively the fraction starting and ending point of the sample $\left(r_{1}\right.$ and $r_{2}$ are such that $0<r_{1}<r_{2}<1$ ). The window size of the regression, defined by $r_{w}=r_{2}-r_{1}$, varies from the fixed initial window $r_{0}$ to the total sample. The PWY (2011) test involves implementation of ADF test on a forward expanding sample sequence. The SADF statistic is obtained as the supremum value of corresponding ADF statistic obtained from equation (3).

Thus, the SADF test is defined as follows:

$$
\operatorname{SADF}\left(r_{0}\right)=\underbrace{\sup }_{r_{0} \leq r_{2} \leq 1} A D F_{0}^{r_{2}}
$$

In order to detect explosive behavior in the series, the supremum value of the ADF statistics obtained is compared with the right tailed critical values of its limit distribution which is given by: 


$$
\underbrace{\sup }_{r_{0} \leq r_{2} \leq 1} A D F_{0}^{r_{2}} \rightarrow \underbrace{\sup }_{r_{0} \leq r_{2} \leq 1} \frac{\int_{0}^{r_{2}} W d W}{\int_{0}^{r_{2}} W^{2} d W}
$$

Where $\mathrm{W}$ is a standard Weiner process that denotes convergence in distribution.

The date-stamping strategy according to the SADF procedure compares each estimate of the statistic $A D F_{0}^{r_{2}}$ sequence to right-tailed critical value of the standard ADF test. The origination date of a bubble, denoted by $T_{r_{e}}$, corresponds to the first chronological observation in which the statistic $A D F_{0}^{r_{2}}$ exceeds the corresponding critical value. The estimated termination date of a bubble, denoted by $T_{r_{f}}$, corresponds to the first chronological observation in which the statistic $A D F_{0}^{r_{2}}$ goes below the corresponding critical value.

The estimates of the origination and the termination date of a bubble using the SADF strategy are defined by:

$$
\begin{aligned}
& \widehat{r_{e}}=\underbrace{\inf }_{r_{0} \leq r_{2} \leq 1}\left\{r_{2} ; A D F_{0}^{r_{2}}>s c u_{\left\lfloor r_{2} T\right]}^{\alpha}\right\} \\
& \widehat{r_{f}}=\underbrace{\inf }_{r_{e} \leq r_{2} \leq 1}\left\{r_{2} ; A D F_{0}^{r_{2}}<s c u_{\left\lfloor r_{2} T\right]}^{\alpha}\right\}
\end{aligned}
$$

Where $s c u_{\left\lfloor r_{2} T\right\rfloor}^{\alpha}$ is the $100(1-\alpha) \%$ critical value of the standard ADF statistic based on $\left\lfloor r_{2} T\right\rfloor$ observations.

\subsubsection{The PSY Test (2015): The Generalized Supremum Augmented Dickey-Fuller Test (GSADF)}

The SADF dating strategy can be inconsistant when the sample contains more than one episode of exuberance. To overcome this weakness, PSY (2015) propose a generalized version of the SADF, named the generalized supremum Augmented Dickey-Fuller (GSADF) test, for testing explosive behavior in the series, date-stamping the origination and collpase when they may be multiple bubbles in the data. The GSADF test is also based on the recursive implementation of a right-tailed ADF tests; however, it extends the sample sequence to a more flexible range. The GSADF test differs from the SADF test by allowing more flexible window widths. Unlike the SADF test which fixes the starting point, $r_{1}$, as the first observation of the sample, the GSADF allows the starting point to vary within the range $\left[0, r_{2}-r_{0}\right]$. PSY (2015) have shown that the modified version of SADF test, which cover more subsamples, is more efficient than the SADF test in detecting explosive behavior when multiple bubbles occur in the data. PSY (2015) define the GSADF statistic as the supremum value of ADF statistic over all feasible ranges of $r_{1}$ and $r_{2}$. Formelly, This statistic is defined as:

$$
\operatorname{GSADF}\left(r_{0}\right)=\underbrace{\sup }_{\substack{r_{0} \leq r_{2} \leq 1 \\ 0 \leq r_{1} \leq r_{2}-r_{0}}} A D F_{r_{1}}^{r_{2}}
$$

Under the null hypothesis, the limit distribution of the GSADF statistic is given by:

$$
\underbrace{\sup }_{\substack{r_{0} \leq r_{2} \leq 1 \\ 0 \leq r_{1} \leq r_{2}-r_{0}}} A D F_{r_{1}}^{r_{2}}\left\{\frac{\frac{1}{2} r_{w}\left[W\left(r_{2}\right)^{2}-W\left(r_{1}\right)^{2}-r_{w}\right]-\int_{r_{1}}^{r_{2}} W(r) d r\left[W\left(r_{2}\right)-W\left(r_{2}\right)\right]}{r_{w}^{1 / 2}\left\{r_{w} \int_{r_{1}}^{r_{2}} W(r)^{2} d r-\left[\int_{r_{1}}^{r_{2}} W(r) d r\right]^{2}\right\}^{1 / 2}}\right\}
$$

According to the GSADF approach proposed by PSY (2015), the first step in dating bubble is to test the unit root hypothesis by comparing $\operatorname{GSADF}\left(r_{0}\right)$ to the $(1-\alpha)$ critical value. $\alpha$ is the nominal significance level. The second step of the procedure is to identify periods of explosive behavior in the series, if the null hypothesis is rejected in the GSADF test. PSY (2015) recommended a date-stamping strategy that is based on backward sup $\mathrm{ADF}(\mathrm{BSADF})$ statistic, defined as:

$$
B S A D F_{r_{2}}\left(r_{0}\right)=\underbrace{\sup }_{0 \leq r_{1} \leq r_{2}-r_{0}} S A D F_{r_{1}}^{r_{2}}
$$

The origination date of the period of exuberance corresponds to the first chronological observation whose BSADF statistic exceeds the critical value:

$$
\widehat{r_{e}}=\underbrace{\inf }_{r_{0} \leq r_{2} \leq 1}\left\{r_{2} ; B S A D F_{0}^{r_{2}}\left(r_{0}\right)>s c u_{\left\lfloor r_{2} T\right]}^{\alpha}\right\}
$$

The estimation termination date of the bubble is defined as the first observation in which the BSADF sequence crosses the corresponding critical value from above:

$$
\widehat{r_{f}}=\underbrace{i n f}_{\widehat{r_{e}} \leq r_{2} \leq 1}\left\{r_{2} ; B S A D F_{0}^{r_{2}}<s c u_{\left[r_{2} T\right]}^{\alpha}\right\}
$$


Where $s c u_{\left\lfloor r_{2} T\right\rfloor}^{\alpha}$ is the $100(1-\alpha) \%$ critical value of the standard ADF statistic based on $\left\lfloor r_{2} T\right\rfloor$ observations.

Since the distributions of both the $\operatorname{SADF}\left(r_{0}\right)$ and $\operatorname{GSADF}\left(r_{0}\right)$ are non-standard, the critical values must be obtained by Monte Carlo simulations. The Monte Carlo procedure is based on the following steps:

1) Generate a random walk series with an asymptotically negligible drift of size $T$.

2) Estimate equation (3) using least squares.

3) Compute the SADF and GSADF statistics.

4) Repeat steps 1-3 a large number of times (2000 replications), to obtain distributions of SADF and GSADF statistics.

5) The $100(1-\alpha) \%$ critical value of each test statistic, derived using Monte Carlo simulation, is given by the $100(1-\alpha)$ percentile of the corresponding distributions obtained in step 4 .

\section{Results and Discussion}

We use the SADF test and the GSADF test to detect periodically speculative bubbles and to estimate the origination and termination dates of bubbles in the Tunisian stock market. Following PSY (2015), we use the price-dividend ratio, for the period extending from January 2004 to December 2014.

The results of the SADF test are presented in Table 1. The latter reproduces the SADF statistic and the corresponding 90\%, 95\% and 99\% critical values. These critical values are derived by Monte Carlo simulation with a number of replications of 2000 . The initial window was fixed at 13 observations which correspond to approximately $10 \%$ of the sample size.

Table 1. The SADF test of the Tunindex price-dividend ratio (sample: monthly data 2004:01 - 2014:12)

\begin{tabular}{llccc}
\hline & \multicolumn{3}{c}{ Critical Values } \\
\cline { 2 - 5 } & & $90 \%$ & $95 \%$ & $99 \%$ \\
\hline SADF & 2.37 & 1.18 & 1.50 & 2.09 \\
\hline
\end{tabular}

Table 1 shows that the SADF statistic exceeds the $1 \%$ right tailed critical values (i.e. $2.37>2.09$ ). This result indicates that we cannot reject the null hypothesis of absence of speculative bubbles and therefore there were significant evidence of exuberance of the Tunindex price-dividend ratio. We conclude from SADF test that the Tunisian stock market is affected by the presence of periodically collapsing bubbles for the period between January 2004 and December 2014.

To date-stamp the episodes of exuberance in stock prices, the SADF statistics sequence is compared to the $95 \%$ SADF critical values sequence. Figure 1 displays graphically the results from the SADF test over the sample period. The graph shows two periods of explosivity (grey areas) and identifies their starting and ending points.

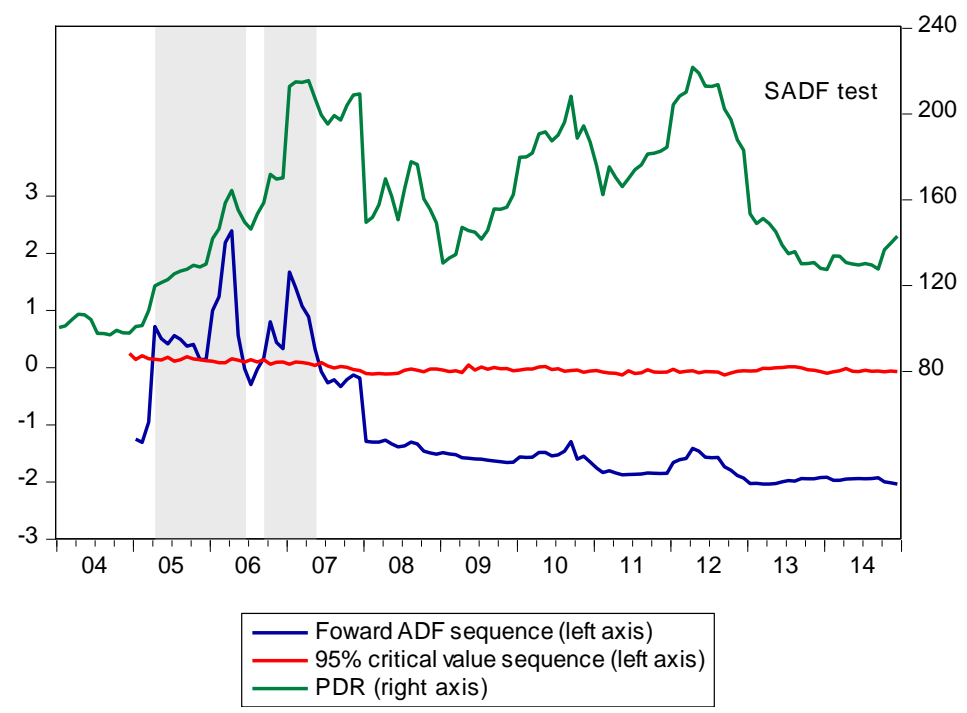

Figure 1. Date-stamping bubble periods in the Tunindex price-dividend ratio: the SADF test 
Table 2 reproduces the results of Figure 1. The PWY (2011) strategy has therefore identified two bubbles. The first bubble started in April of 2005 and collapsed in June of 2006. Three months later, a second bubble was detected. This bubble started in September 2006 and ended in May 2007.

Table 2. Bubble periods in the Tunindex price-dividend ratio: the SADF test

\begin{tabular}{ccc}
\hline Starting Date & Ending Date & Duration (months) \\
\hline April 2005 & June 2006 & 14 \\
September 2006 & May 2007 & 10 \\
\hline
\end{tabular}

These results are interesting at first glance, however they seem to be insufficient because they do not disclose the period of turbulence experienced by the Tunisian stock market during the pre and post revolution period (i.e. 2010-2011). PSY (2015) argue, when there may be multiple bubbles in the data, the SADF strategy may suffer from reduced discriminatory power and than fails to detect the existence of bubbles.

The application of the PSY (2015) method allows us to overcome the weakness associated with the SADF procedure. Table 3 displays the results from the GSADF test. The value of the GSADF statistic obtained from sample data, which is 4.00 , is greater than the critical value (3.58) at the $10 \%$ significance level. The result shows that the null hypothesis of no explosive behavior in the price-dividend ratio should be rejected at $10 \%$ level. We conclude that the Tunisian stock market is caracterised by periodically collapsing speculative bubbles over the sample period.

Table 3. The GSADF test of the Tunindex real price-dividend ratio (sample: monthly data 2004:01 - 2014:12)

\begin{tabular}{lllll}
\hline & \multicolumn{3}{c}{ Critical Values } \\
\cline { 2 - 4 } & & $90 \%$ & $95 \%$ & $99 \%$ \\
\hline GSADF & 4,00 & 3,58 & 4,07 & 4,98 \\
\hline
\end{tabular}

Figure 8 displays results for the date-stamping procedure based on the GSADF test. It shows that the two explosive periods detected by the SADF method were grouped into a single episode. This strategy also identifies two other episodes of explosiveness and collapse.

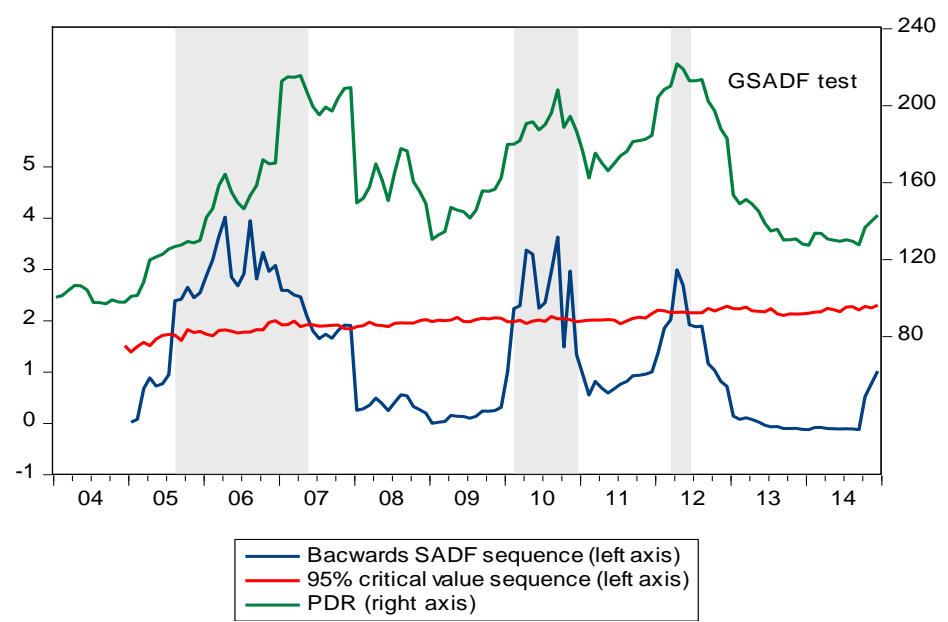

Figure 2. Date-stamping bubble periods in the Tunindex price-dividend ratio: the GSADF test

Table 4 summarizes the origination date and the collapse date of explosive bubbles using the GSADF strategy.

Table 4. Bubble periods in the Tunindex price-dividend ratio: the GSADF test

\begin{tabular}{ccc}
\hline Starting Date & Ending Date & Duration (months) \\
\hline August 2005 & May 2007 & 22 \\
February 2010 & December 2010 & 11 \\
March 2012 & June 2012 & 4 \\
\hline
\end{tabular}


From table 4, we see that the PSY (2015) approach identified three periodically collapsing bubbles over the sample period. The first bubble occurs between August 2005 and May 2007. This bubble corresponds to the two bubble episodes detected by the SADF method. The origination date of the bubble in August 2005 can be explained by a general euphoria on small-cap stocks due to the announcement of some foreign investors intention, to invest in Tunisia. The year 2006 was marked by an increase of stock market prices which driven by the anticipation of good performance of the securities. In addition, the 2007 Finance Act were introduced new tax provisions to stimulate investment and encourage IPOs has kept this increase. A downward movement was then started towards the end of May 2007. This regression was initiated by the big capitalizations of the place which has been severely corrected by shareholders and was irrationally reproduced on fundamentally solid values. This correction can explain the collapse of bubble.

The GSADF procedure allows us to identify a second periodically collapsing bubble that started in February 2010 and ended in December 2010. The formation of this bubble is related to speculative movement experienced by the market at the year 2010 beginning. The stock market performance of the year 2009 would probably be the origin of this speculative movement. This movement of speculation which, combined with high liquidity, can explain the origin of the formation of the bubble. The liquidity of the market was boosted by the wave of IPOs during 2010. In fact, in September 2010, Tunindex reached an historical level of 5681.39 points, i.e. an increase by about $32.8 \%$. However, in October 2010, the announcement of a bill on the taxation of capital gains on the stock market, was badly perceived by the investors who operated significant securities sales. Thereby, a movement of panic was initiated yielding a drop of $10 \%$ in the index during the year's last quarter. Moreover, the social movements wave combined with the bad perception of this bill, led to a confidence crisis in the stock market which can explain the bubble bursting in December 2010.

The bubble between March 2012 and June 2012 had the shortest duration. The Tunindex experienced a slight recovery from February 2012, which continued until April of the same year. This upward movement can be explained by a slight economic recovery, confirmed by the statistics published by the National Institute of Statistics. This phase coincided with the date of formation bubble. For its collapse in June 2012, it could be explained by the behavior of investors in the market.

\section{Conclusion}

This study investigates the existence of rational speculative bubbles in the Tunisian stock market during the period extending from January 2004 to December 2014. We apply new econometric bubble detection strategies proposed by PWY (2011) and PSY (2015). The major advantage of these strategies is that they allow identification of bubbles as well as estimation the beginning and the end of bubbles episodes. The empirical evidence from the application of these methods to the Tunindex price-dividend ratio confirms the existence of exuberance and date-stamps its origination and termination. The SADF strategy locates only two episodes of exuberance and collapse in the Tunisian stock market. The first bubble occurred between April 2005 and June 2006. The second bubble started in September 2006 and ended in May 2007. However, we can observe that the GSADF method groups together the two episodes of bubbles detected by the SADF method in a single episode and detect two other explosive episodes. Such results show that the GSADF approach outperform the SADF strategy in detecting periodically collapsing bubbles when multiple bubbles occur in the data.

\section{References}

Blanchard, O. J. (1979). Speculative Bubbles, Crashes and Rational Expectations. Economics Letters, 3(4), 387-389. https://doi.org/10.1016/0165-1765(79)90017-x

Blanchard, O. J., \& Watson, M. W. (1982). Bubbles, Rational Expectations, and Financial Markets. National Bureau of Economic Research Working Paper Series, 945, 1-30. https://doi.org/10.3386/w0945

Bohl, M. T. (2003). Periodically Collapsing Bubbles in the US Stock Market? International Review of Economics and Finance, 12(3), 385-397. https://doi.org/10.1016/s1059-0560(02)00128-4

Boubaker, A., Nguyen, D. K., \& Taouni, I. (2007). Rational Speculative Bubbles: Theory and Empirics in Tunisian Stock Market. Paper presented at 4th International Finance Conference, 15-17 March, Hammamet, Tunisia. Retrieved from http://khuongnguyen.free.fr/Paper_Nguyen_Boubaker.pdf

Brooks, C., \& Katasaris, A. (2003). Rational Speculative Bubbles: An Empirical Investigation of the London Stock Exchange. Bulletin of Economic Research, 55(4), 319-346. https://doi.org/10.1111/1467-8586.00179

Camerer, C. (1989). Bubbles and Fads in Asset Prices. Journal of Economic Surveys, 3(1), 3-41. https://doi.org/10.1111/j.1467-6419.1989.tb00056.x 
Cassidy, J. (2010). Interview with Eugene Fama. New Yorker Magazine, 13(01). Retrieved from http://www.newyorker.com/online/blogs/johncassidy/2010/01/interview-with-eugenefama.html

Central Bank of Tunisia. (2004-2015). Annual Report. Retrieved from https://www.bct.gov.tn

Central Bank of Tunisia. (2004-2015). Financial Statistics Bulletin (pp. 149-191). Retrieved from https://www.bct.gov.tn

Chang, T., Ranjbar, O., Aye, G. C., \& Gupta, R. (2014). Testing for Multiple Bubbles in the BRICS Stock Markets. Working Paper, Department of Economics, University of Pretoria, 7, 1-22. Retrieved from https://www.up.ac.za/media/shared/Legacy/sitefiles/file/40/677/wp_2014_071.pdf

Cutler, D. M., Poterba, J. M., \& Summers, L. H. (1991). Speculative Dynamics. The Review of Economic Studies, 58(3), 529-546. https://doi.org/10.2307/2298010

Diba, B., \& Grossman, H. (1988). Explosive Rational Bubbles in Stock Prices? The American Economic Review, 78 (3), 520-530. Retrieved from http://www.jstor.org/stable/1809149

Dickey, D. A., \& Fuller, W. A. (1981). Likelihood Ratio Statistics for Autoregressive Time Series with a Unit Root. Econometrica, 49(4), 1057-1072. https://doi.org/10.2307/1912517

Driffill, J., \& Sola, M. (1998). Intrinsic Bubbles and Regime Switching. Journal of Monetary Economics, 42(2), 357-373. https://doi.org/10.1016/s0304-3932(98)00021-x

Enders, W., \& Granger, C. W. J. (1998). Unit-Root Tests and Asymmetric Adjustment with an Example Using the Term Structure of Interest Rates. Journal of Business and Economic Statistics, 16(3), 304-311. https://doi.org/10.2307/1392506

Enders, W., \& Siklos, P. L. (2001). Cointegration and Threshold Adjustment. Journal of Business and Economic Statistics, 19(2), 166-176. https://doi.org/10.1198/073500101316970395

Engle, R., \& Granger, C. W. J. (1987). Co-integration and Error Correction: Representations, Estimation and Testing. Econometrica, 55(2), 251-276. https://doi.org/10.2307/1913236

Evans, G. W. (1991). Pitfalls in Testing for Explosive Bubbles in Asset Prices. The American Economic Review, 81(4), 922-930. Retrieved from http://www.jstor.org/stable/2006651

Froot, K., \& Obstfeld, M. (1991). Intrinsic Bubbles: The Case of Stock Prices. The American Economic Review, 81(5), 1189-1214. Retrieved from http://www.jstor.org/stable/2006913

Granger, C. W. (1986). Developments in the Study of Cointegrated Economic Variables. Oxford Bulletin of Economics and Statistics, 48(3), 213-228. https://doi.org/10.1111/j.1468-0084.1986.mp48003002.x

Gürkaynak, R. S. (2008). Econometric Tests of Asset Price Bubbles: Taking Stock. Journal of Economic Surveys, 22(1), 166-186. https://doi.org/10.1111/j.1467-6419.2007.00530.x

Hall, S., Psaradakis, Z., \& Sola, M. (1999). Detecting Periodically Collapsing Bubbles: A Markov-Switching Unit Root Test. Journal of Applied Econometrics, 14(2), 143-154. https://doi.org/10.1002/(sici)1099-1255(199903/04)14:2\%3C143::aid-jae500\%3E3.0.co;2-x

Hausman, J. A. (1978). Specification Tests in Econometrics. Econometrica, 46(6), 1251-1271. https://doi.org/10.2307/1913827

Homm, U., \& Breitung, J. (2012). Testing for Speculative Bubbles in Stock Markets: A Comparison of Alternative Methods. Journal of Financial Econometrics, 10(1), 198-231. https://doi.org/10.1093/jjfinec/nbr009

Kindleberger, C. P. (1991). Bubbles. In J. Eatwell., M. Milgate, \& P. Newman (Eds.), The World of Economics (pp. 20-22). The New Palgrave. Palgrave Macmillan, London. http://doi.org/10.1007/978-1-349-21315-3_3

LeRoy, S., \& Porter, R. (1981). The Present-Value Relation: Tests Based on Implied Variance Bounds. Econometrica, 49(3), 555-574. https://doi.org/10.2307/1911512

Liu, Z., Han, D., \& Wang, S. (2016). Testing Bubbles: Exuberance and collapse in the Shanghai A-share stock market. China's New Sources of Economic Growth, 1, 247-269. https://doi.org/10.22459/cnseg.07.2016.11

McQueen, G., \& Thorley, S. (1994). Bubbles, Stock Returns, and Duration Dependence. Journal of Financial and Quantitative Analysis, 29(03), 379-401. https://doi.org/10.2307/2331336

Mehri, H. S. (2017). Détection et Datation des Bulles Spéculatives Rationnelles: Cas du Marché Boursier Tunisien (Unpublished doctoral dissertation). Institut Supérieur de Gestion, Tunis, Tunisie. 
Phillips, P. C. B., \& Perron, P. (1988). Testing for a Unit Root in Time Series Regression. Biometrika, 75(2), 335-346. https://doi.org/10.1093/biomet/75.2.335

Phillips, P. C. B., Shi, S. P., \& Yu, J. (2015). Testing for Multiple Bubble: Historical Episodes of Exuberance and Collapse in the S\&P500. International Economic Review, 56(4), 1043-1078. https://doi.org/10.1111/iere.12132

Phillips, P. C. B., Wu, Y., \& Yu, J. (2011). Explosive Behavior in the 1990s Nasdaq: When did Exuberance Escalate Asset Values? International Economic Review, 52(1), 201-226. https://doi.org/10.1111/j.1468-2354.2010.00625.x

Reuters, T. (2008). Datastream global equity indices User Guide Issue 5. Retrived from http://www.datastream.jp/wp/wp-content/uploads/2017/02/DatastreamGlobalEquityIndicesUGissue05.pdf

Shiller, R. J. (1981). Do Stock Prices Move Too Much to be Justified by Subsequent Changes in Dividends? The American Economic Review, 71(3), 421-436. Retrieved from http://www.jstor.org/stable/1802789

Shiller, R. J. (1984). Stock Prices and Social Dynamics. Brookings Papers on Economic Activity, 15(2), 457-510. https://doi.org/10.2307/2534436

Summers, L. H. (1986). Does the Stock Market Rationally Reflect Fundamental Values? The Journal of Finance, 41(3), 591-601. https://doi.org/10.2307/2328487

Taylor, M., \& Peel, D. (1998). Periodically Collapsing Stock Price Bubbles: A Robust Test. Economics Letters, 61(2), 221-228. https://doi.org/10.1016/s0165-1765(98)00171-2

Tunis Stock Exchange. (2004-2015). Annual Report. Retrieved from http://www.bvmt.com.tn/

Van Norden, S. (1996). Regime Switching as a Test for Exchange Rate Bubbles. Journal of Applied $\begin{array}{llll}\text { Econometrics, } & 11 & \text { 219-251. }\end{array}$ https://doi.org/10.1002/(sici)1099-1255(199605)11:3\%3C219::aid-jae394\%3E3.3.co;2-j

Van Norden, S., \& Schaller, H. (1999). Speculative Behavior, Regime-Switching, and Stock Market Crashes. In P. Rothman (Eds.), Nonlinear Time Series Analysis of Economic and Financial Data. Dynamic Modeling and Econometrics in Economics and Finance, 1, Springer, Boston, MA. https://doi.org/10.1007/978-1-4615-5129-4_15

Van Norden, S., \& Vigfusson, R. (1998). Avoiding the pitfalls: Can regime-switching tests reliably detect bubbles? Studies in Nonlinear Dynamics and Econometrics, 3(1), 1-22. https://doi.org/10.2202/1558-3708.1038

Wang, X. (2014). Episodes of Exuberance in Emerging Equity Markets and the Global Financial Crisis. Retrieved from http://macro.soc.uoc.gr/docs/Year/2015/papers/paper_1_53.pdf

West, K. (1987). A Specification Test for Speculative Bubbles. The Quarterly Journal of Economics, 102(3), 553-580. https://doi.org/10.2307/1884217

\section{Notes}

Note 1. See Cassidy (2010).

Note 2. See Gurkaynak (2008) for an overview of the literature.

\section{Copyrights}

Copyright for this article is retained by the author(s), with first publication rights granted to the journal.

This is an open-access article distributed under the terms and conditions of the Creative Commons Attribution license (http://creativecommons.org/licenses/by/4.0/). 